\title{
Meconium Aspiration Syndrome: Pathophysiology and Prevention
}

\author{
Mary Celeste Klingner, MD, and Jerry Kruse, MD, MSPH
}

Background: Despite the common occurrence of intrauterine meconium passage and resultant meconium aspiration syndrome (MAS), controversies regarding the pathophysiology and use of appropriate preventive strategies abound.

Metbods: Databases from MEDLINE, MD Consult, and the Science Citation Index were searched from 1964 to the present to find relevant sources of information.

Results and Conclusions: Meconium passage occurs by three distinct mechanisms: (1) as a physiologic maturational event, (2) as a response to acute hypoxic events, and (3) as a response to chronic intrauterine hypoxia. Meconium passage might merely be a marker of chronic intrauterine hypoxia or can predispose to aspiration of meconium and resultant inflammatory pneumonitis, surfactant inactivation, and mechanical airway obstruction. Aspiration can occur in utero with fetal gasping, or after birth with the first breaths of life. Many cases of MAS can be prevented by the strategies addressed in this article, but some will occur despite appropriate preventive techniques. There is not enough evidence to support the use of amnioinfusion as a standard of care for all pregnancies complicated by meconium. Pharyngeal suctioning before delivery of the shoulders is an effective preventive intervention, as is the combination of pharyngeal suctioning followed by intubation and tracheal suctioning. Suctioning of the trachea may be done on a selective basis depending on fetal vigor and consistency of meconium. ( $\mathrm{J}$ Am Board Fam Pract 1999;12:450-66.)

Meconium is the green viscous fluid that consists of fetal gastrointestinal secretions, cellular debris, mucus, blood, lanugo, and vernix. It first appears in the fetal ilium between 10 and 16 weeks' gestation. ${ }^{1}$ Passage of meconium in utero with staining of the amniotic fluid occurs in $12 \%$ to $16 \%$ of all deliveries $^{2-5}$ and often is not associated with fetal distress or neonatal death or disability. Meconium passage is rare before 34 weeks of gestational age. ${ }^{6}$ Meconium passage occurs in up to $20 \%$ of fullterm gestations and can occur in more than $35 \%$ of pregnancies continuing beyond 42 weeks' gestation. $^{7-10}$ Meconium passage most commonly occurs in small-for-gestational-age and postmature infants. It occurs in association with cord complications and other factors, such as chronic medical conditions or conditions associated with intrauter-

Submitted, revised, 12 May 1999.

From the Department of Family and Community Medicine, Southern Illinois University School of Medicine, Quincy Family Practice Program (MCK, JK), Quincy, Ill. Address reprint requests to Jerry Kruse, MD, MSPH, Quincy Family Practice Program, 2325 Elm Street, Quincy II. 62301 . ine growth retardation, which can compromise the uteroplacental circulation. ${ }^{11}$

Meconium aspiration is defined as the presence of meconium below the vocal cords. This finding occurs in $20 \%$ to $30 \%$ of all infants with meconium-stained amniotic fluid. ${ }^{12}$ Meconium aspiration syndrome (MAS) classically has been defined as respiratory distress that develops shortly after birth, with radiographic evidence of aspiration pneumonitis and a history of meconium-stained fluid. More recently, because of the wide array of possible radiographic findings, MAS had been defined simply as respiratory distress in an infant born through meconium-stained amniotic fluid whose symptoms cannot otherwise be explained. ${ }^{4}$

MAS occurs in about $5 \%$ of deliveries with meconium-stained amniotic fluid ${ }^{12}$ and is one of the most common causes of neonatal respiratory distress. Infants born through meconium-stained amniotic fluid are about 100 times more likely to develop respiratory distress than those born through clear fluid. ${ }^{13}$ Even in women at very low risk for obstetric complications, meconium-stained amniotic fluid is common and is associated with a 
fivefold increase in perinatal mortality compared with low-risk patients with clear amniotic fluid. ${ }^{5}$ Death occurs in about $12 \%$ of infants with MAS, ${ }^{4}$ and MAS is associated with about $5 \%$ of all of perinatal deaths. ${ }^{4,12}$ MAS is also associated with neonatal seizures and chronic seizure disorders. ${ }^{13}$

Some generally accepted concepts regarding the pathophysiology of meconium passage and the management of meconium aspiration have been challenged in recent years. One such concept is the belief that there is a strong independent association between meconium passage and fetal distress. A recent controversial review by Katz and Bowes, ${ }^{14}$ however, concluded that there exists no independent association between meconium passage and fetal distress. Though this study has been criticized, ${ }^{12}$ it has focused attention upon meconium passage being related in large part to maturational events only and not to intrauterine stress or hypoxia. We will address such controversies in this article, discuss a rational approach to the pregnancy complicated by meconium-stained amniotic fluid, and address the following questions:

1. What is the relative importance of each of the various causes of intrauterine meconium passage?

2. What are the pathophysiologic mechanisms of meconium aspiration and the development of MAS?

3. What morbidity and mortality are caused directly by aspirated meconium, and to what degree is meconium merely a marker of prolonged intrauterine gestation or the result of chronic hypoxia?

4. What is the clinical relevance of the consistency (thickness) of meconium?

5. What measures are effective in the prevention of MAS? In particular, what is the efficacy of amnioinfusion, pharyngeal suction before delivery of the shoulders, endotracheal intubation and suction, and other preventive measures?

\section{Methods}

The MEDLINE database was searched from 1964 to the present using the key terms "meconium," "aspiration," and "amnioinfusion" in combinations. The MD Consult database was searched from 1995 to the present using the same terms. Other sources were then found by back referencing these articles, by searching the Science Citation Index, and by reviewing recent texts.

\section{Pathophysiology of Meconium Aspiration Cause of Meconium Passage}

There are multiple causative factors of meconium passage. Meconium passage in utero has been attributed to a fetal response to intrauterine stress ${ }^{15}$ and is often associated with fetal hypoxia, asphyxia, and acidosis. ${ }^{16-18}$ Hypoxia causes increased gastrointestinal peristalsis and relaxed anal sphincter tone. Transient compression of the umbilical cord or fetal head also causes a vagal response, which can result in meconium passage. ${ }^{19,20}$

Meconium in the amniotic fluid can also simply represent the maturation of fetal intestinal function. Meconium passage is rare before 34 weeks' gestation, and its incidence increases only slightly through 37 weeks' gestation. After 37 weeks' gestation, its incidence increases steadily with increasing gestational age. ${ }^{6,7,9}$ Passage of meconium in the mature fetus is facilitated by myelination of nerve fibers, an increase in parasympathetic tone, ${ }^{1}$ and increases in the concentration of motilin (a peptide that stimulates the contraction of the intestinal muscle). ${ }^{21-23}$ An association between fetal distress and elevated levels of motilin has been reported. ${ }^{21,22}$

\section{Mecbantsms of Meconium Asptration and Mecontum Aspiration Syndrome}

The pathophysiology of meconium aspiration and MAS is complex, and the timing of the initial insult resulting in MAS remains controversial. Intrauterine fetal gasping, mechanical airway obstruction, pneumonitis, surfactant inactivation, and damage of umbilical vessels all play roles in the pathophysiology of meconium aspiration. There is also a strong association between MAS and persistent pulmonary hypertension of the newborn (PPHN).

\section{Fetal Gasping}

The traditional belief was that meconium aspiration occurs immediately after birth. ${ }^{12,24,25}$ When the newborn exposed to meconium begins respiration outside the womb, aspirated particulate or thick meconium can be carried rapidly by the first breaths to the distal airways. Studies of neonatal puppies with tantalum-labeled meconium instilled into the trachea before the first breath have confirmed that the distal migration of particulate matter can occur within 1 hour of birth. ${ }^{26}$

Several investigators have suggested, however, that most cases of meconium aspiration occur in 
utero when fetal gasping is initiated before delivery. Block et $\mathrm{al}^{27}$ found that hypoxia and hypercarbia in fetal baboons induced intrauterine gasps and meconium aspiration. Gooding et $\mathrm{al}^{26}$ on the other hand, failed to find intrauterine gasping or meconium aspiration by hypoxic fetal dogs. Retrospective reviews provide indirect evidence that some cases of meconium aspiration in humans are prenatal rather than postnatal events. For example, meconium has been found distally as far as the alveoli in some stillborn infants and in some infants that die within hours of delivery. ${ }^{28-30}$ Thus, it is believed that MAS will sometimes occur despite appropriate airway management at delivery. There is currently no way to distinguish between the infant who has developed MAS by intrauterine respiration or gasping and the infant who has developed MAS by inhalation of meconium at the first breaths after delivery.

\section{Mechanical Obstruction of the Airway}

It is commonly thought that the initial and most important problem of the infant with MAS is obstruction caused by meconium in the airways. Complete obstruction of large airways by thick meconium is an uncommon occurrence. The exact incidence of large-airway obstruction is unknown, though Thureen et al, ${ }^{28}$ in an autopsy study of infants who died of MAS, found no evidence of such obstruction. Usually, small amounts of meconium migrate slowly to the peripheral airways. This mechanism can create a ball valve phenomenon, in which air flows past the meconium during inspiration but is trapped distally during expiration, leading to increases in expiratory lung resistance, functional residual capacity, and anteroposterior diameter of the chest. ${ }^{1,12}$ Regional atelectasis and ventilation-perfusion mismatches develop from total obstruction of the small airways. Adjacent areas often are partially obstructed and overexpanded, leading to pneumothorax and pneumomediastinum air leaks. ${ }^{31,32}$ Pulmonary air leaks are ten times more likely to develop in infants with meconium aspiration than those without, and leaks often develop during resuscitation. ${ }^{1}$ These obstructive airway phenomena lead to the classic radiographic findings of MAS shown in Figure 1: atelectasis, pneumothorax, and hyperexpanded areas of the lung. Consolidation, pleural effusions, and relatively normal radiographic appearances can occur.

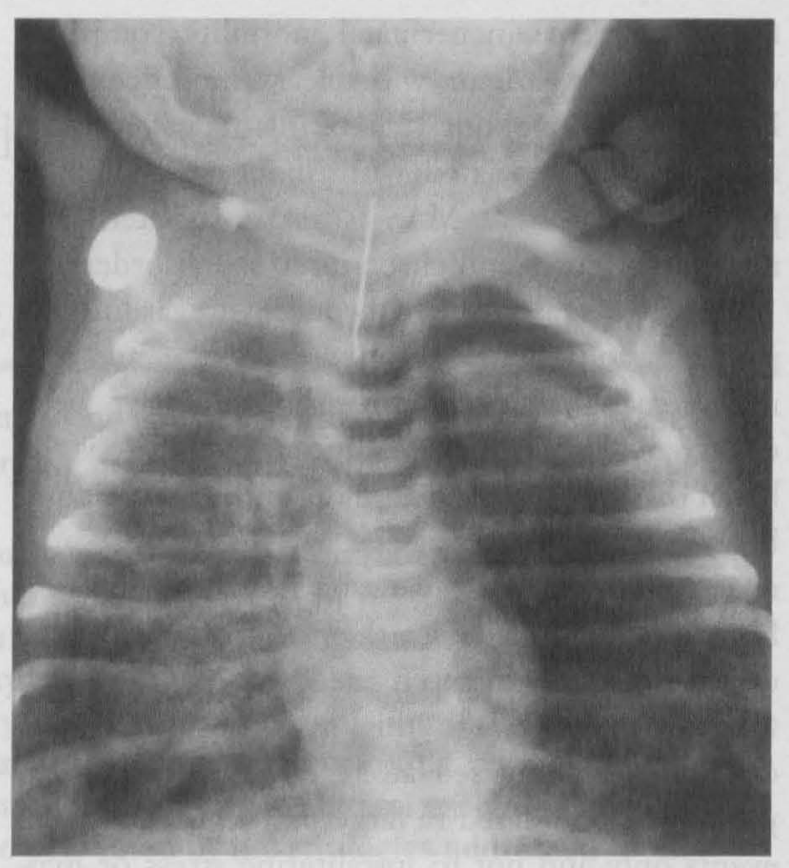

Figure 1. Chest radiograph of a full-term infant with meconium aspiration showing coarse interstitial infiltrates and left pneumothorax.

The severity of radiographic findings does not accurately predict the severity of illness. ${ }^{4,33,34}$

\section{Pneumonitis}

Pneumonitis is a usual feature of MAS, occurring in about one half of the cases. ${ }^{11,35}$ An intense inflammatory response in the bronchi and alveoli can occur within hours of aspiration of meconium. ${ }^{36-40}$ The airways and lung parenchyma become infiltrated with large numbers of polymorphonuclear leukocytes and macrophages, which produce local injury by release of inflammatory mediators and reactive oxygen species. ${ }^{41,42}$ Depending upon the degree of hypoxia, hyaline membranes, pulmonary hemorrhage, and vascular necrosis can occur. ${ }^{36}$

An example of meconium pneumonitis is shown in Figure 2.

The inflammatory response is caused by chemotactic cytokines (such as interleukin 8) in meconium. ${ }^{42}$ The inflammatory response itself leads to high levels of vasoactive mediators (eg, thromboxanes, leukotrienes, and prostaglandins). ${ }^{43,44}$ Such vasoactive mediators play a role in the development of PPHN. ${ }^{45-47}$ Antiinflammatory treatments, such as systemic steroids, can become important in the prevention of serious lung injury in cases of meconium aspiration. ${ }^{48,49}$ 


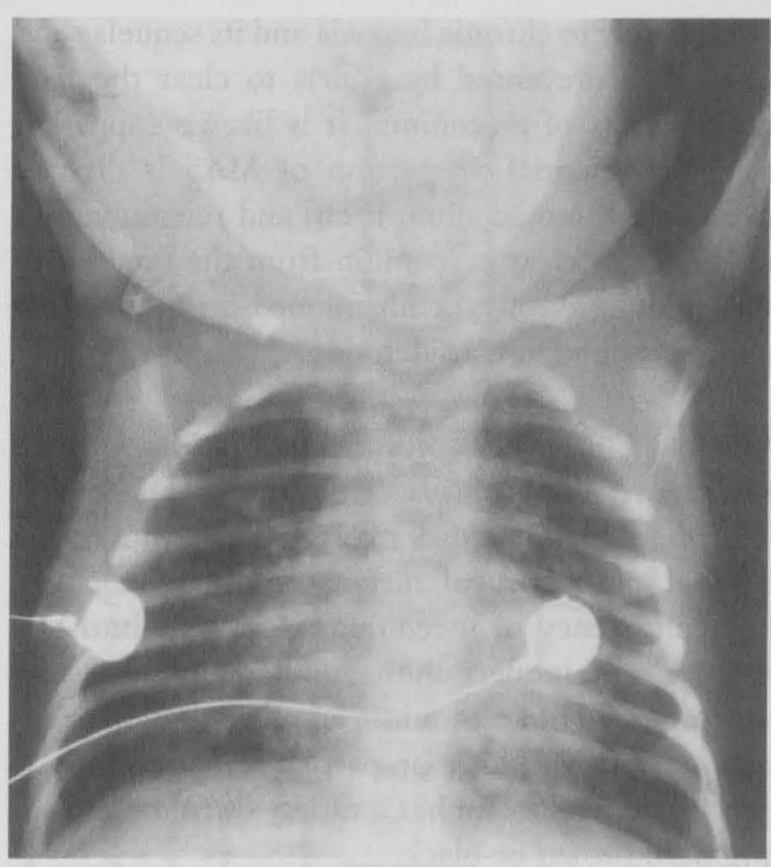

Figure 2. Chest radiograph of a full-term infant with coarse interstitial infiltrates of meconium aspiration pneumonitis.

\section{Surfactant Inactivation}

Proteins and fatty acids in aspirated meconium can interfere with surfactant function. Meconium aspiration syndrome in humans is mediated, in part, by inactivation of endogenous surfactant. ${ }^{50-52}$ Atelectasis, decreased lung compliance, intrapulmonary shunting, and hypoventilation are aggravated by inhibition of surfactant function.

Moses and colleagues ${ }^{50}$ found that surfactant inhibition is related both to the consistency (thickness) of the meconium and the concentration of the surfactant itself. At low concentrations of surfactant, very dilute meconium inhibited surfactant function, whereas thick meconium was unable to affect surfactant function at high concentrations of surfactant. ${ }^{50}$ This information suggested that preterm infants or those with thick meconium might benefit from treatment with exogenous surfactant. One small randomized trial $(n=40)$ of infants with MAS who were given intermittent boluses of highdose surfactant found improvement in all parameters measured (oxygenation, resolution of PPHN, number of air leaks, need for extracorporal membrane oxygenation and duration of mechanical ventilation)..$^{53}$ Other observational studies have provided conflicting results concerning the efficacy and proper administration of surfactant for
MAS. ${ }^{54-57}$ Cleary and Wiswell ${ }^{4}$ suggest that the optimal dose, type, concentration, and method of administration (bolus, infusion, or lavage) of surfactant for MAS have yet to be determined, and that more rigorous investigation is needed before widespread use of such therapy.

\section{Umbilical Vessel Damage}

The effect of meconium on the various fetal tissues differs greatly. Meconium exposure to the placental membranes and chorionic plate results in only slight inflammation. Inflammation and focal injury of the umbilical vessels, however, may be quite severe. ${ }^{35}$ Meconium-induced cord vessel wall injury adversely affects vessel function by inducing spasm and necrosis, with potential fetal hypoperfusion. $^{58,59}$ Altshuler et $\mathrm{al}^{59}$ found meconium-induced umbilical vascular necrosis in $1 \%$ of meconium-stained placentas. Cesarean delivery for fetal distress was needed in $60 \%$ of the cases with umbilical vascular necrosis.

\section{Persistent Pulmonary Hypertension of the Newborn}

PPHN is common in neonates with fatal MAS. Indeed, a majority of cases of PPHN are associated with $\mathrm{MAS}^{60}$ and this condition could be the final common pathway for the severe morbidity and mortality seen in infants with MAS. Both acute pulmonary arterial vasoconstriction and abnormally thick muscularization of the intraacinous arteries are important elements in the pathophysiology of PPHN.

Vasoconstriction of the pulmonary arteries can be caused by hypoxia as a result of any of the mechanisms discussed above (mechanical obstruction, chemical inflammation, or inactivation of surfactant). Chronic hypoxia caused by other factors can also lead to PPHN through the development of abnormal pulmonary arterial muscularization. This histologic finding reflects a chronic change that likely develops before birth, not as a response to acute meconium aspiration. Thus, meconium passage associated with PPHN can be both a direct pathogenic cause of lung damage and a simple marker of chronic intrauterine hypoxia. The difficulty in managing PPHN and MAS is addressed by Wiswell and Bent, ${ }^{12}$ who write: "whatever the cause of PPHN, which is concomitant with MAS, the vicious cycle of shunting, hypoxemia, and acidosis can lead to further pulmonary hypertension 
that may be difficult or impossible to successfully treat."

\section{Relative Importance of Patbophysiologic Mecbanisms}

The information presented in the previous section raises the question of the relative importance of the various pathophysiologic mechanisms of meconium passage and aspiration. Is meconium itself a direct primary cause of neonatal morbidity and mortality? Or is meconium harmless itself and merely a marker of fetal maturation or of chronic fetal hypoxia?

Recent studies of small groups of patients have attempted to delineate the relative importance of the pathophysiologic mechanisms. Carbonne and colleagues, ${ }^{61}$ in their study of fetal pulse oximetry in labors complicated by meconium passage, found evidence that MAS was primarily associated with acute hypoxic events late in labor. In contrast, Thureen et $\mathrm{al}^{28}$ found that meconium aspiration is often a chronic prenatal disease rather than a condition related to acute events that occur late in labor or after birth.

Ramin et al ${ }^{62}$ studied umbilical cord blood gases of more than 7000 term infants with meconiumstained amniotic fluid. Less than $1 \%$ of these infants developed MAS, and of these, about one half had an associated acute acidemia at birth. Because most acidemic fetuses had abnormally increased $\mathrm{PCO}_{2}$ levels (rather than pure metabolic acidemia) the authors concluded that many of the cases of fetal compromise associated with MAS were acute events. They hypothesized that "the pathophysiology of MAS includes, but is not limited to, fetal hypercarbia, which stimulates fetal respiration leading to intrauterine aspiration of meconium into the alveoli, and lung parenchymal damage secondary to acidemia induced alveolar cell damage in the presence of meconium." They further noted that this pathophysiologic sequence did not account for the other half of cases of MAS because these neonates were not acidemic at birth, and other unidentified (potentially chronic) factors were responsible for these other cases of MAS.

The current understanding of the complex pathophysiologic mechanisms of MAS and associated PPHN is summarized in Figure 3. Though the relative importance of each mechanism is not completely understood, it is apparent from the studies previously reviewed that many cases of MAS are related only to chronic hypoxia and its sequelae and cannot be prevented by efforts to clear the fetal nasopharynx of meconium. It is likewise apparent that a substantial proportion of MAS is directly caused by the meconium itself, and recommended measures to clear meconium from the fetal nasopharynx should not be abandoned on the basis of pathophysiologic considerations.

\section{Clinical Considerations \\ Consistency of Meconium}

There are a few studies regarding the importance of the consistency of meconium. ${ }^{63-65}$ Generally, the consistency of meconium is divided into two categories: thin meconium, and thick or particulate meconium. Thin meconium is yellow to light green and is watery. Thick or particulate meconium is pasty or granular and has a variety of colors including dark brown or black.

Thin meconium occurs in $10 \%$ to $40 \%$ of the cases of meconium passage. ${ }^{63-65}$ There is a relation between the consistency and timing of meconium passage. The risk of perinatal death is increased five to seven times when thick meconium is present at the onset of labor. ${ }^{64-66}$ Thick meconium early in labor generally reflects low amniotic fluid volume, a risk factor for neonatal morbidity and mortality itself. Infants with thin meconium are more likely to have passed meconium as a physiologic maturational process and are more likely to be healthy at birth. ${ }^{12,64,67,68}$

The finding of either thick or thin meconium at the onset of labor reflects events that occurred before labor. Meconium that is detected during labor after clear fluid has passed indicates an acute event. In this instance, the risk of perinatal morbidity and mortality is intermediate between the high risk associated with the passage of thick meconium and the lower risk associated with the passage of thin meconium before rupture of membranes. ${ }^{64}$

There are no studies that address the effect on neonatal morbidity and mortality of immediate delivery by cesarean section when thick meconium is present or suspected early in labor. It has been recommended, however, that all labors with meconium-stained amniotic fluid should be continuously monitored. ${ }^{17,69-71}$

\section{Prevention of Meconium Aspiration Syndrome}

The different mechanisms of the passage of meconium and the development of MAS have given rise 


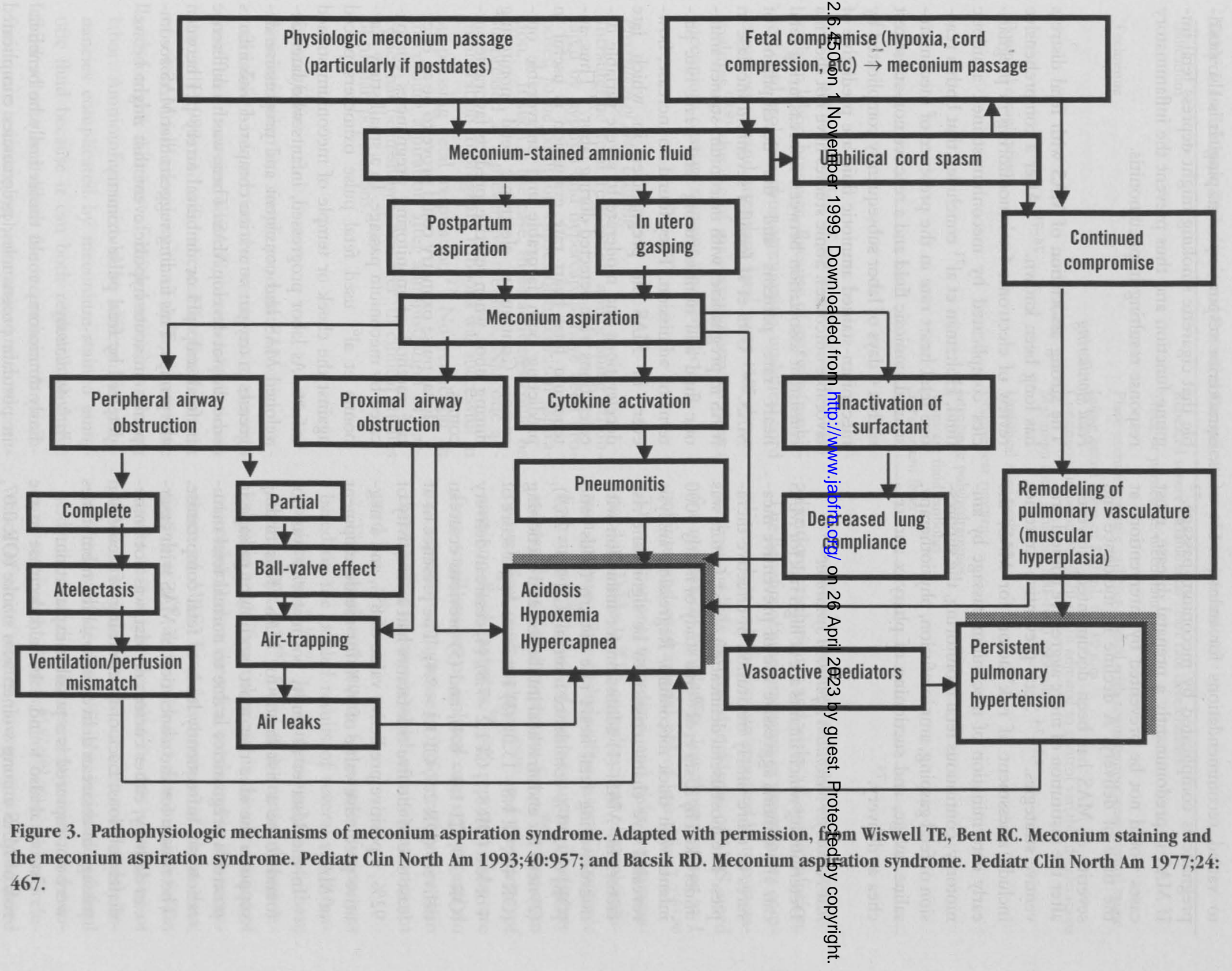


to varied recommendations for management of pregnancies complicated by meconium passage. ${ }^{72}$ If MAS is predominantly a prenatal disease, most cases would not be prevented by interventions at the time of delivery. A decline in incidence and severity of MAS has been documented, however, after the institution of more aggressive clinical preventive strategies. ${ }^{9,73,74}$ Such preventive strategies include assessment of risk factors for MAS, the early determination of meconium passage by amniotomy, continuous fetal monitoring, the suppression of fetal gasping, amnioinfusion, physiotherapy, saline lavage, and suctioning of pharynx and trachea at delivery. ${ }^{75}$

\section{Risk Factors for Meconium Aspiration Syndrome}

Determining which infants are at high risk for MAS can allow more aggressive use of preventive measures or more timely institution of effective therapies. The most useful delineation of risk factors was undertaken by Usta et $\mathrm{al}^{70}$ in a study of nearly 1000 infants with thick meconium. Regression analysis revealed five characteristics to be significant risk factors for MAS: (1) admission for induction with nonreassuring fetal heart rate pattern (odds ratio [OR] 6.9, 95\% confidence interval [CI] 1.8 - 26.9), (2) need for endotracheal intubation and suctioning (OR 4.9, CI 1.8 - 13.0), (3) 1-minute Apgar score of 4 or less (OR 3.1, CI 1.2 - 7.8), (4) cesarean delivery (OR 3.0, CI 1.4 - 6.4), and (5) previous cesarean delivery (OR 2.5, CI $1.1-5.4$ ). The presence of at least one of the five risk factors had a sensitivity of $92 \%$, a positive predictive value of $8 \%$, and a negative predictive value of $99 \%$ for the development of MAS.

In the Usta et al study, postmaturity was not found to be a risk factor for MAS. This finding supports the idea that most meconium passage in postterm pregnancies is due to normal fetal maturation and infrequently leads to fetal compromise. The reason for the association of MAS with cesarean delivery, either current or past, was not immediately obvious. Lack of forewarning of meconium passage in cesarean deliveries in which membranes were not ruptured is a possible explanation.

Usta et al also found a 14-fold decrease in the risk of MAS among women who smoke (OR 0.07 , CI $0.009-0.63){ }^{70}$ The reason for this strong association is also unknown. Possible explanations include accelerated lung maturity as a result of chronic intrauterine fetal stress or inhibition of intrauterine respiration or gasping. It is also possible that cigarette smoking might depress fetal immune function and thus prevent the inflammatory response resulting in pneumonitis.

\section{Fetal Monitoring}

The strong association of MAS with fetal distress has long been known. ${ }^{76-79}$ After a comprehensive review of electronic fetal monitoring in pregnancies complicated by meconium-stained amniotic fluid, Holtzman et $\mathrm{al}^{71}$ concluded that both a reactive fetal heart rate in the presence of meconiumstained amniotic fluid and a reactive non-stress test within 4 days of labor subsequently complicated by meconium-stained amniotic fluid are predictive of favorable outcomes. Some studies have not shown a consistent association between nonreassuring fetal heart rate patterns and the development of MAS. ${ }^{70,71}$ Usta et al found a sevenfold increase in MAS in pregnancies with meconium-stained amniotic fluid and nonreassuring fetal heart rate patterns on admission. They found no increase, however, in MAS in pregnancies in which late decelerations and moderate to severe variable decelerations were detected during labor.$^{70}$ Thus, antepartum fetal heart rate evaluation is useful in predicting both favorable and unfavorable outcomes. Continuous electronic fetal monitoring during labor, when reactive, predicts favorable outcomes.

Fetal pulse oximetry could prove to be an effective method of monitoring pregnancies complicated by meconium passage. In a small study Carbonne et $a^{61}$ used fetal pulse oximeters placed against the cheek or temple of meconium-stained infants. As labor progressed, infants who later developed MAS had consistent and progressive decreases in oxygen saturation compared with infants who did not develop MAS. There was no difference in fetal scalp $\mathrm{pH}$ or umbilical artery $\mathrm{pH}$ between the groups. This finding suggests that MAS accompanies an acute hypoxic event that might be well detected by fetal pulse oximetry.

\section{Early Amniotomy}

Early amniotomy could theoretically be beneficial in postdate pregnancies, pregnancies complicated by abnormal fetal heart rate patterns, or pregnancies accompanied by other high-risk factors to assess risk and allow for proper preparation to manage those complicated by meconium passage. 
Table 1. Indications, Technique, and Potential Complications of Amnioinfusion.

\begin{tabular}{ll}
\hline Indications & Repeated severe variable fetal heart rate decelerations \\
& Thick or particulate meconium \\
Technique & Place uterine pressure catheter primed with room-temperature normal saline \\
& Infuse initial bolus of $250 \mathrm{~mL}$ for $30 \mathrm{~min}$ \\
& Continuous infusion of $10-20 \mathrm{~mL} / \mathrm{h}$ adjusted to control variable decelerations \\
& Maximum total infusion: $800-1000 \mathrm{~mL}$ saline \\
Potential complications & Umbilical cord prolapse \\
& Uterine scar rupture \\
& Iatrogenic polyhydramnios \\
& Amniotic fluid embolus \\
Intrapartum fever
\end{tabular}

There are no studies of such use of amniotomy early in labor, however. Because of its risks (umbilical cord prolapse, chorioamnionitis, umbilical cord compression, and attendant fetal heart rate abnormalities, ${ }^{80,81}$ the use of early amniotomy to detect meconium passage remains problematic.

\section{Prevention of Fetal Gasping}

Intrauterine fetal respiration and gasping stimulated by hypoxia and hypercapnia have been proposed to be common causes of meconium aspiration. ${ }^{23}$ If such is the case, these activities could be suppressed as a preventive measure. Narcotic administration to pregnant baboons was successful in suppressing fetal respiration. ${ }^{27}$ No reduction in meconium aspiration after administration of narcotics has been shown, however, in clinical studies of human populations. ${ }^{82,83}$

\section{Amnioinfusion}

Amnioinfusion is a simple procedure in which normal saline is infused into the uterine cavity through a catheter. It was introduced into clinical practice in the early 1980s and was indicated for the treatment of severe variable deceleration of the fetal heart rate and for the dilution of thick meconium during labor. Amnioinfusion could be effective in pregnancies complicated by meconium-stained amniotic fluid because it can both replenish amniotic fluid volume and dilute the meconium. Amnioinfusion can correct oligohydramnios and cord compression, which cause hypoxia and hypercapnia. Aspiration of diluted meconium with the first breaths might be less likely to cause MAS than aspiration of thick particulate meconium.
Weismiller ${ }^{84}$ recently reviewed the benefits, indications, technique, and risks of amnioinfusion. The benefits of amnioinfusion in pregnancies complicated by thick meconium reported in two metaanalyses include decreased incidence of MAS, need for mechanical ventilation, low Apgar scores at 1 minute, and cord arterial $\mathrm{pH}$ of less than $7.2 .^{85,86}$ The indications, technique, and risks are summarized in Table 1 . The complications of amnioinfusion are rare. They include a few cases of iatrogenic hydramnios, ${ }^{87}$ a case of uterine rupture, ${ }^{87}$ slightly increased rates of intrapartum fever, ${ }^{88}$ a few cases of umbilical cord prolapse, ${ }^{89,90}$ and five cases of amniotic fluid embolus. ${ }^{91}$ All reported risks are from small studies or isolated case reports and do not represent an increase in incidence of more than that expected in cases in which amnioinfusion is not used.

The initial enthusiasm for amnioinfusion was based on the pooled results of several small randomized trials. ${ }^{92-98}$ In a meta-analysis of these studies, Dye et $\mathbf{a l}^{85}$ found that amnioinfusion resulted in a significant decrease in the occurrence of meconium below the vocal cords and in the occurrence of MAS. In a later review of these data, Cusick et al ${ }^{99}$ also concluded that amnioinfusion results in a slight decrease in the occurrence of MAS. Amnioinfusion has not been consistently associated with decreases in the incidence of fetal acidemia, fetal distress, cesarean section, and neonatal respiratory distress. ${ }^{85,92-102}$ The clinical relevance of these studies, however, was questioned because of methodologic difficulties. ${ }^{103}$

In review of more recent information, Spong et $\mathrm{al}^{98,104}$ concluded that amnioinfusion solely for meconium-stained amniotic fluid is not more ben- 
eficial than therapeutic amnioinfusion for repetitive variable decelerations in pregnancies complicated by meconium-stained amniotic fluid.

The current data are not sufficient to recommend amnioinfusion in all pregnancies complicated by thick meconium. Amnioinfusion is more useful in pregnancies complicated by both thick meconium and variable decelerations than with either condition alone. Further studies are needed before amnioinfusion becomes the standard of care for all pregnancies complicated by meconium-stained amniotic fluid.

\section{Physiotherapy and Saline Lavage}

Various types of chest physiotherapy (postural drainage, percussion, vibration) have been proposed to help remove aspirated meconium. There is no evidence to support these approaches in either neonatal resuscitation or the later treatment of MAS. Other unproved and potentially dangerous methods of physiotherapy (eg, cricoid pressure or epiglottal blockage with one or two fingers to prevent meconium from descending the infant's airway, and manual thorax compression before endotracheal compression) should be avoided. ${ }^{4}$ Tracheal suction with saline lavage has also been proposed. This strategy is controversial, and respiratory complications have been reported as a result of this procedure. $^{73}$

\section{Pharyngeal and Tracheal Suctioning}

Because the histologic findings of intense pneumonitis and the radiographic findings of bronchial obstruction suggested a direct pathogenic role for aspirated meconium, suctioning to clear the fetal pharynx and trachea of meconium at birth became common practice in the early 1970s. Suctioning of the pharynx through the mouth and nares by the delivering attendant was recommended after the delivery of the head and before the delivery of the shoulders. Routine laryngoscopy with intubation and tracheal suctioning by the attendant caring for the child also became common practice. Such suctioning became widespread despite lack of objective evidence of benefit.

Retrospective studies have shown a decrease in incidence and severity of MAS in infants who underwent combined pharyngeal and tracheal suctioning. $9,73,74$ In a comprehensive review, Wiswell et $\mathrm{al}^{105}$ report a $30 \%$ decrease in the number of cases of MAS that occurred in the 15 years (1973-
1988) immediately following widespread institution of aggressive combined suctioning. The early studies did not delineate the relative benefit of pharyngeal vs tracheal suctioning.

Subsequently, pharyngeal suctioning before delivery of the shoulders has been found to be associated with less need for mechanical ventilation, higher Apgar scores, and fewer radiographic abnormalities. ${ }^{106}$ Its use in labors complicated by meconium-stained amniotic fluid is almost universally supported. ${ }^{4}$

The efficacy of tracheal suctioning has been more difficult to prove. Because of potential complications of intubation and tracheal suctioning, the selective use of tracheal suctioning based upon the thickness of meconium and the degree of fetal vigor has gained favor.

Fetal hypoxia, bradycardia, and increased intracranial pressure, though transient, are not uncommon during fetal intubation. ${ }^{107}$ Tracheal suctioning can also induce pulmonary artery spasm in infants with pulmonary hypertension ${ }^{108}$ and is associated with an increased rate of infection. ${ }^{109,110}$ Stridor following tracheal suctioning is rare and transient. ${ }^{63,111}$ The incidence of transient side effects is very low in the hands of experienced clinicians, and several retrospective studies have shown no lasting adverse sequelae after tracheal intubation and suctioning. $3,68,112$

The efficacy of selective tracheal suctioning has been studied mainly in an observational or retrospective manner. ${ }^{73,113-116}$ No randomized prospective trials have been performed. In the observational studies, meconium-exposed infants who did not undergo tracheal suctioning were those who were exposed to thin meconium, were full term at birth, and had a birth weight of greater than $2500 \mathrm{~g}$, heart rates after delivery of 100 beats per minute or more, and high anticipated Apgar scores. Application of these selective criteria result in tracheal suctioning in about one half of deliveries complicated by meconium-stained amniotic fluid.

Yoder, ${ }^{113}$ in a study of almost 800 meconiumexposed infants, found that a selective approach to tracheal suctioning based successively upon consistency of meconium and fetal vigor resulted in no increase in neonatal morbidity or mortality. In this study, infants born through thin meconium received routine pharyngeal suctioning with a bulb syringe only. In deliveries complicated by thick meconium, infants received suctioning before de- 
livery of the shoulders with a 10 French or greater diameter suction catheter or with a bulb syringe. Only infants with poor tone or cry underwent visualization of the glottis. Intubation and tracheal suctioning were done only if meconium was noted in the glottic area. MAS occurred in $11 \%$ of the infants who underwent tracheal suctioning, in $3 \%$ of infants with moderate to thick meconium who did not meet further criteria for tracheal suctioning, and in none of the infants with thin meconium.

Peng et al ${ }^{114}$ studied more than 600 meconiumexposed infants. All infants received pharyngeal suctioning with a wall-mounted De Lee suction device before delivery of the shoulders. No endotracheal intubation was done if the infants fulfilled all of the following criteria: vaginal delivery, gestational age of more than 37 weeks, birth weight more than $2500 \mathrm{~g}$, and anticipated Apgar score of 8 or more at 1 minute. None of the 322 meconiumexposed infants who did not undergo tracheal suctioning developed MAS.

After pharyngeal suctioning, $20 \%$ to $55 \%$ of infants exposed to meconium have the substance below the vocal cords ${ }^{11,63,65,83,115}$ In a study of 133 infants at low risk for meconium aspiration (thin meconium, no meconium in the hypopharynx, fetal vigor) who did not undergo tracheal suctioning, Wiswell and Henley ${ }^{3}$ found that $9 \%$ developed MAS. From such indirect evidence, the conclusion has been drawn that universal tracheal suctioning will reduce the incidence of MAS. The current information allows physician discretion in the application of universal or selective tracheal suctioning.

\section{Recommendations for Prevention of Meconium Aspiration Syndrome}

Several organizations have proposed expert guidelines for the management of infants exposed to meconium-stained amniotic fluid. In 1992, the Committee on Neonatal Ventilation and Meconium of the American Heart Association recommended that all infants exposed to meconiumstained amniotic fluid have obstetric pharyngeal suctioning. They further recommended that tracheal suctioning be performed if (1) there is evidence of fetal distress, (2) the infant's responses are depressed or the infant requires positive pressure ventilation, (3) there is thick or particulate meconium, or (4) obstetric pharyngeal suctioning was not performed. This committee left the manage- ment of the following situations to individual discretion: (1) infants who have been exposed to thin meconium, (2) infants who are active and vigorous, and (3) infants who have been suctioned before delivery of the shoulders. ${ }^{17}$ These recommendations are the basis for the current joint guidelines of the American Academy of Pediatrics and the American Heart Association regarding meconium. ${ }^{18}$ Given the current lack of large, randomized trials of selective vs universal tracheal suctioning, these guidelines offer a rational clinical approach to the management of the labor complicated by meconium passage. A clinical approach that does not include the thickness of meconium as a criterion for tracheal suctioning can also be supported by current data. Recommendations for the prevention of MAS based upon the combined guidelines discussed above and other evidence are displayed in Table 2 and illustrated in Figures 4 through 7.

\section{Discussion}

Issues related to the management of intrauterine meconium passage have generated considerable controversy. Meconium passage is a common occurrence, complicating one in eight pregnancies, and MAS is associated with many cases of neonatal respiratory distress, long-term respiratory and neurologic complications, and death. It is unlikely that the incidence of meconium passage will decrease substantially. If MAS and its various complications are to decrease, all health care professionals who attend deliveries should have an understanding of the controversies surrounding the management of meconium-stained amniotic fluid and be well versed in the proper obstetric and neonatal interventions.

Clinical protocols for the management of meconium-stained amniotic fluid have been adopted but often are not evidence-based. Health care professionals should carefully assess the quality of current information and make clinical decisions in a hierarchical fashion, recognizing when an intervention is necessary and when clinical judgment allows a range of appropriate decisions and interventions. An understanding of the complex pathophysiology of meconium passage and of the efficacy of various interventions to prevent MAS is necessary for appropriate clinical judgments to be made.

Clinical decision making is based on an understanding of the pathophysiology of meconium pas- 
Table 2. Recommendations for the Prevention of Meconium Aspiration Syndrome.

All attendants at delivery should have expertise in evaluating and treating pregnancies complicated by meconium-stained amniotic fluid

After detection of meconium, continuous fetal monitoring should be performed

The delivery room should be prepared for pharyngeal suctioning, tracheal suctioning, and resuscitation. All equipment should be checked for proper working order

After delivery of the head and before delivery of the shoulders, the mouth, nose, and pharynx should be suctioned with a large-bore $(10 \mathrm{~F}-14 \mathrm{~F})$ suction catheter using wall suction or a De Lee trap. A bulb syringe may be used if a catheter is not available (Figure 4)

If there has been evidence of fetal distress or thick meconium, or if infant vigor is depressed (poor muscular tone or heart rate below 100 beats per minute), the infant should be transferred immediately after delivery to a prepared warm environment. Assessment of infant vigor should be done immediately with no delay for assignment of Apgar score

The vocal cords should be visualized with a laryngoscope, and any residual meconium in the hypopharynx or about the cords should be removed with a large-bore catheter (Figure 5)

The trachea should then be intubated with the appropriatesized endotracheal tube and the lower airway suctioned (Figure 6). Preferably, suction should be applied directly to the tube with a meconium aspirator (Figure 7) as the tube is slowly withdrawn. A meconium aspirator with a continuous pressure of -80 to $-150 \mathrm{~mm} \mathrm{Hg}$ is most effective in removing meconium. ${ }^{119}$ A suction catheter should not be introduced through the endotracheal tube

If a substantial amount of meconium is returned by suction, the intubation and suction should be repeated until there is clearing of aspirated material

Alternatively, tracheal suctioning may be performed directly with a large-bore catheter, though this technique is more difficult than intubation

Ventilation and other resuscitative measures should be used between episodes of suctioning if oxygenation is needed, even if the meconium has not been completely cleared

After initial stabilization, the suction catheter may be advanced through the mouth to the stomach and the infant's stomach emptied of meconium that could later be regurgitated and aspirated.

sage. There is strong evidence most meconium passage occurs by each of three basic mechanisms: (1) as a physiologic maturational event, (2) as a response to acute hypoxic events occurring late in pregnancy, and (3) as a response to chronic intrauterine hypoxia. There is some evidence that the risk of development of MAS and other serious complications is quite different for each of these three basic mechanisms.

Meconium passed as a maturational event is of thin consistency in most cases. MAS and other serious complications occur infrequently in this circumstance. Even though complications are rare, passage of thin meconium is a common occurrence,

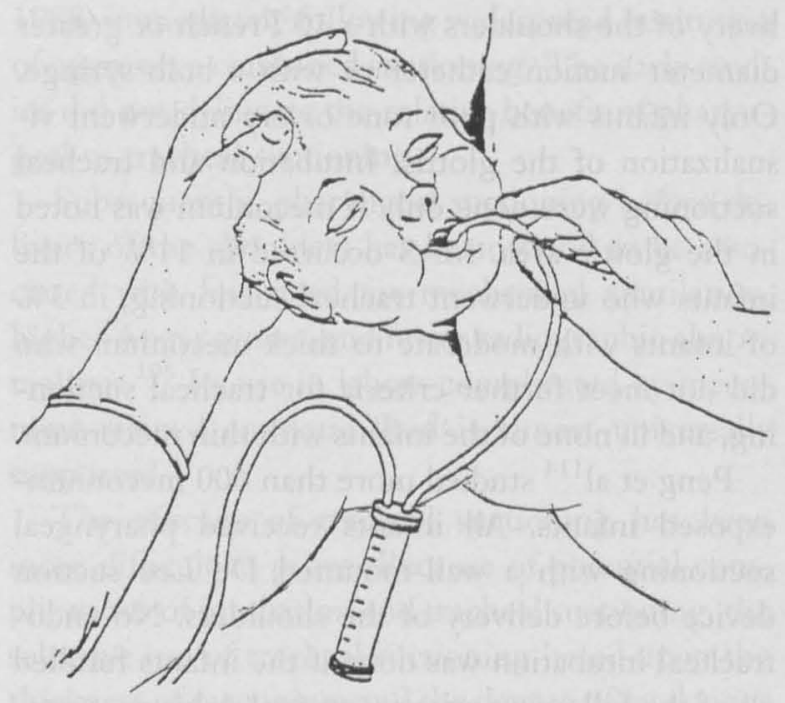

Figure 4. Pharyngeal suctioning of an infant before delivery of the shoulders. Reprinted with permission from Bloom RS, Cropley C, AHA/AAP Neonatal Resuscitation Program Steering Committee. Textbook of neonatal resuscitation: Elk Grove Village, IIl. American Academy of Pediatrics, 1994.

and $10 \%$ to $20 \%$ of cases of MAS occur in infants born through meconium of thin consistency. ${ }^{4,120,121}$

Infants with acute hypoxic events, near and after the onset of labor, are more likely to pass thick

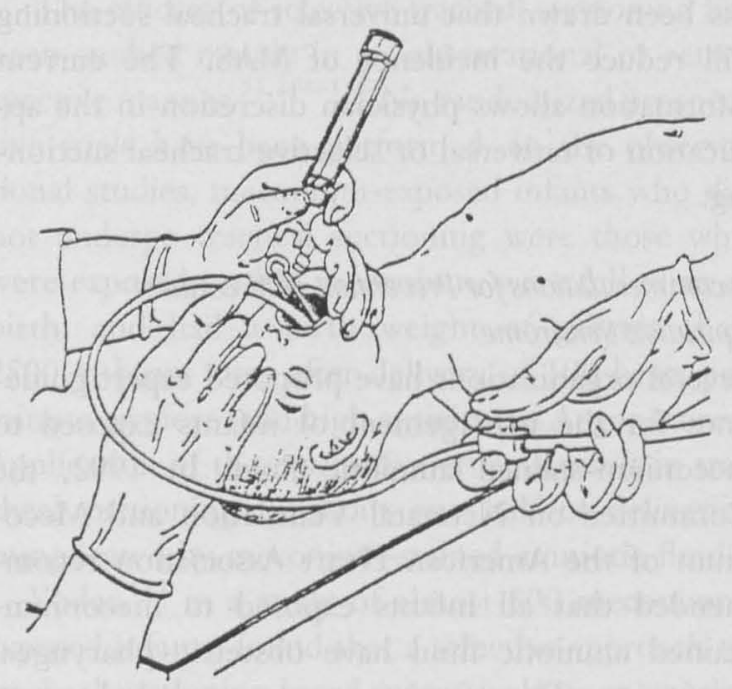

Figure 5. Removal of meconium from the hypopharynx and larynx using a large-bore catheter. Reprinted with permission from Bloom RS, Cropley C, AHA/AAP Neonatal Resuscitation Program Steering Committee. Textbook of neonatal resuscitation: Elk Grove Village, Ill. American Academy of Pediatrics, 1994. 


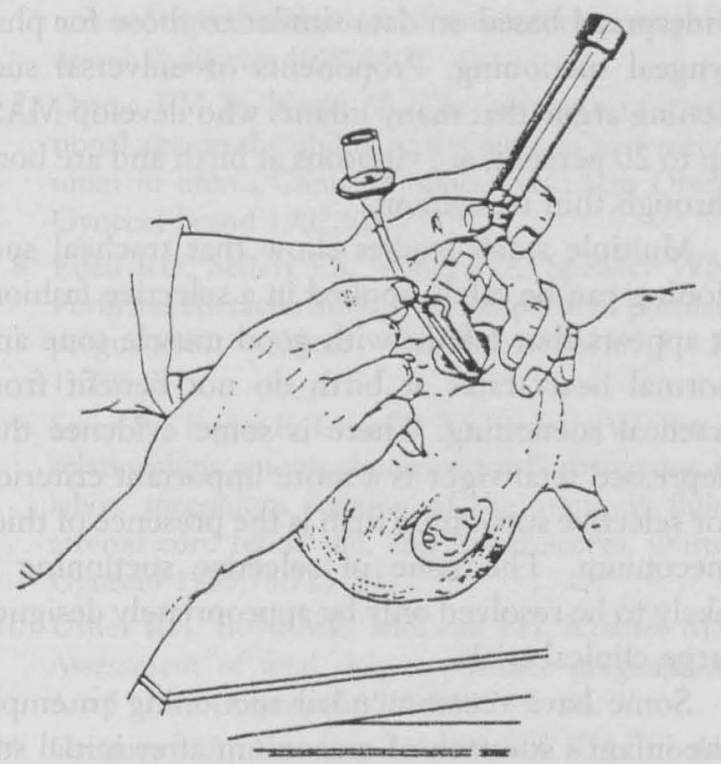

Figure 6. Endotracheal intubation for removal of meconium in the lower airway. Reprinted with permission from Bloom RS, Cropley C, AHA/AAP Neonatal Resuscitation Program Steering Committee. Textbook of neonatal resuscitation: Elk Grove Village, Ill. American Academy of Pediatrics, 1994.

meconium and to suffer meconium aspiration. Interventions to clear meconium are more likely to be beneficial for these infants than for infants born through thin meconium. Aspiration of meconium with the first breaths after birth is more likely, and

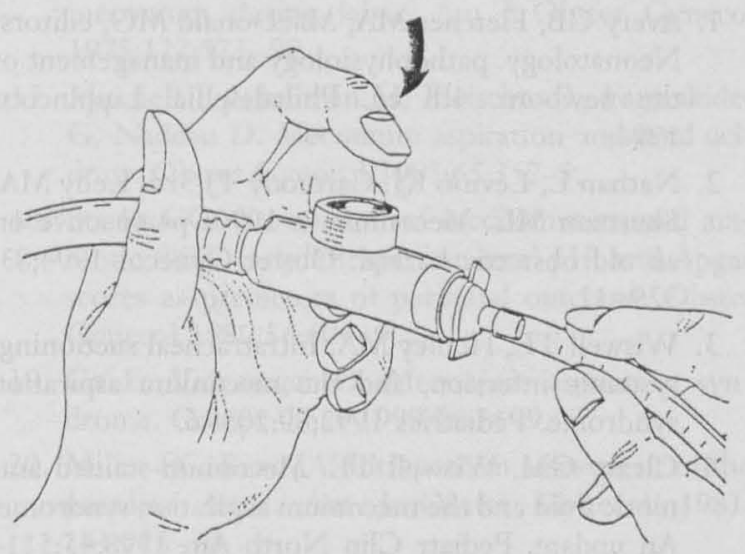

Figure 7. Meconium aspirator attached to wall suction. Reprinted with permission from Bloom RS, Cropley C, AHA/AAP Neonatal Resuscitation Program Steering Committee. Textbook of neonatal resuscitation: Elk Grove Village, Ill. American Academy of Pediatrics, 1994. the infants are at higher risk for the obstructive and local inflammatory effects of meconium.

Infants who suffer chronic intrauterine hypoxia are more likely to develop abnormal pulmonary arterial muscularization and persistent pulmonary hypertension of the newborn, and subsequently their responses are more depressed at birth. Chronic hypoxia and hypercapnia stimulate both meconium passage and neonatal gasping. In such cases, meconium aspiration can occur long before birth. Complications could be due to either the aspiration of meconium, the conditions causing chronic hypoxia, or both. Meconium aspiration might be merely a marker of chronic intrauterine hypoxia, and efforts to clear meconium from the infant's pharynx and trachea will be ineffective in preventing the effects of meconium aspiration in some cases. These infants are more likely to suffer from long-term respiratory and neurologic complications. Whether suctioning will decrease the incidence or severity of these long-term adverse events is not known.

It is apparent that there is some overlap between the pathophysiologic mechanisms shown in Figure 3 , and it is impossible to determine precisely the relative frequency of each, or which of the mechanisms is responsible for meconium passage in a given infant. The complexity suggests that a simple clinical protocol for management of pregnancies complicated by meconium will be difficult to develop. Proper clinical decisions will be based upon careful clinical assessment and the timely application of a variety of interventions. Some cases of MAS will not be prevented despite appropriate airway management and other appropriate interventions.

A number of widely used interventions for the prevention of MAS, including methods to remove meconium from the respiratory tract and the treatment of conditions predisposing to meconium aspiration, deserve comment. The estimated benefit of any intervention relies upon the inherent attributes of the intervention and the previous assessment of risk factors. Infants at greatest risk for MAS are those at high risk for intrauterine hypoxia, those born through thick meconium, those delivered by repeat or emergency cesarean section, and those whose fetal vigor is depressed at birth. Abnormal fetal heart rate patterns and fetal pulse oximetry best predict which infants will have depressed fetal vigor at birth. The finding of meco- 
nium passage in utero should prompt a thorough evaluation of the patient for general high-risk factors in pregnancy and the institution of continuous monitoring for fetal well-being.

Early amniotomy in all pregnancies to search for meconium has not been proven to be beneficial. Early amniotomy has been suggested for postdate pregnancies and for pregnancies complicated by other high-risk factors, (eg, abnormal fetal heart rate patterns, evidence of intrauterine growth retardation, chronic and acute medical complications of pregnancy). There are insufficient data to recommend for or against early amniotomy in these circumstances.

Amnioinfusion to prevent MAS has generated great controversy. The current body of knowledge does not allow amnioinfusion to be recommended as standard of care in all pregnancies complicated by meconium. It probably is most effective in pregnancies complicated by both meconium and variable decelerations.

There is no evidence to support maternal narcotic administration (to reduce the occurrence of fetal gasping), saline lavage, or various methods of physiotherapy (including postural drainage, chest percussion, vibratory therapy, and cricoid pressure) for infants born through meconium-stained amniotic fluid. These therapies are not without complications, might further depress an already compromised infant, and could delay the institution of more effective therapies.

The most effective interventions for prevention of MAS include various methods to remove meconium from the pharynx, trachea, and stomach during and immediately after delivery. Pharyngeal suctioning performed by the delivering attendant before the delivery of the shoulders has become almost universally accepted. The evidence for pharyngeal suctioning is based upon a large body of data that show dramatic decreases in MAS and neonatal morbidity and mortality after the institution of widespread pharyngeal suctioning for meconium-stained amniotic fluid.

Tracheal suctioning, on the other hand, is a matter of great controversy. Arguments are made for tracheal intubation and suctioning in all pregnancies complicated by meconium (universal suctioning), for suctioning based upon the degree of infant vigor and the thickness of meconium (selective suctioning), and for no suctioning in any case. Universal suctioning became and has remained widespread based on data similar to those for pharyngeal suctioning. Proponents of universal suctioning argue that many infants who develop MAS, up to 20 percent, are vigorous at birth and are born through thin meconium.

Multiple small studies show that tracheal suctioning can be safely applied in a selective fashion. It appears that infants with good muscle tone and normal heart rates at birth do not benefit from tracheal suctioning. There is some evidence that depressed fetal vigor is a more important criterion for selective suctioning than is the presence of thick meconium. The issue of selective suctioning is likely to be resolved only by appropriately designed large clinical trials.

Some have recommended suctioning to empty the infant's stomach of meconium after initial stabilization. This maneuver is done to remove meconium that later could be regurgitated and aspirated. Though this procedure has become a standard of care, there is insufficient evidence to recommend for or against it. If used, this procedure should be done only after other useful suctioning and resuscitative procedures, and if the infant is stable.

Many cases of MAS can be prevented by assessment of risk factors, continuous fetal monitoring, and appropriate removal of meconium from the infant's pharynx and trachea. Several controversies in the prevention of MAS will be resolved only by large randomized clinical trials.

\section{References}

1. Avery GB, Fletcher MA, MacDonald MG, editors. Neonatology. pathophysiology and management of the newborn. 4th ed. Philadelphia: Lippincott, 1994.

2. Nathan L, Levino KJ, Carmody TJ 3rd, Kelly MA, Sherman ML. Meconium: a 1990 s perspective on an old obstetric hazard. Obstet Gynecol 1994;83: 329-32.

3. Wiswell TE, Henley MA. Intratracheal suctioning, systemic infection, and the meconium aspiration syndrome. Pediatrics 1992;89:203-6.

4. Cleary GM, Wiswell TE. Meconium-stained amniotic fluid and the meconium aspiration syndrome. An update. Pediatr Clin North Am 1998;45:51129.

5. Maymon E, Chaim W, Furman B, Ghezzi F, ShohamVardi I, Mazor M. Meconium stained amniotic fluid in very low risk pregnancies at term gestation. Eur J Obstet Gynecol Reprod Biol 1998;80:16973.

6. Mathews TG, Warshaw JB. Relevance of the ges- 
tational age distribution of meconium passage in utero. Pediatrics 1979;64:30-1.

7. Ostrea EM Jr, Naqui M. The influence of gestational age on the ability of the fetus to pass meconium in utero. Clinical implications. Acta Obstet Gynecol Scand 1982;61:275-7.

8. Eden RD, Seifert LS, Winegar A, Spellacy WN. Perinatal characteristics of uncomplicated postdate pregnancies. Obstet Gynecol 1987;69(3 Pt 1):296-9.

9. Steer PJ, Eigbe F, Lissauer TJ, Beard RW. Interrelationships among abnormal cardiotocograms in labor, meconium staining of the amniotic fluid, arterial cord blood $\mathrm{pH}$, and Apgar scores. Obstet Gynecol 1989;74:715-21.

10. Usher RH, Boyd ME, McLean FH, Kramer MS. Assessment of fetal risk in postdate pregnancies. Am J Obstet Gynecol 1988;158:259-64.

11. Gregory GA, Gooding CA, Phibbs RH, Tooley WH. Meconium aspiration in infants-a prospective study. J Pediatr 1974;85:848-52.

12. Wiswell TE, Bent RC. Meconium staining and the meconium aspiration syndrome. Unresolved issues. Pediatr Clin North Am 1993;40:955-81.

13. Fleischer A, Anyaegbunam A, Guidetti D, Randolph G, Merkatz IR. A persistent clinical problem: profile of the term infant with significant respiratory complications. Obstet Gynecol 1992;79:18590.

14. Katz VL, Bowes WA Jr. Meconium aspiration syndrome: reflections on a murky subject. Am J Obstet Gynecol 1992;166(1 Pt 1):171-83.

15. Fugikura T, Klionsky B. The significance of meconium staining. Am J Obstet Gynecol 1975;121:4550.

16. Miller FC, Sacks DA, Yeh SY, et al. Significance of meconium during labor. Am J Obstet Gynecol 1975;122:573-80.

17. Mitchell J, Schulman H, Fleischer A, Farmakides G, Nadeau D. Meconium aspiration and fetal acidosis. Obstet Gynecol 1985;65:352-5.

18. Starks GC. Correlation of meconium-stained amniotic fluid, early intrapartum fetal $\mathrm{pH}$, and Apgar scores as predictors of perinatal outcome. Obstet Gynecol 1980;56:604-9.

19. Co E, Vidyasagar D. Meconium aspiration syndrome. Compr Ther 1990;16:34-9.

20. Miller FC, Read JA. Intrapartum assessment of the postdate fetus. Am J Obstet Gynecol 1981; 141:516-20.

21. Lucas A, Adrian TE, Aynsley-Green A, Bloom SR. Gut hormones in fetal distress. Lancet 1979;2:968.

22. Lucas A, Christofides ND, Adrian TE, Bloom SR, Aynsley-Green A. Fetal distress, meconium, and motilin. Lancet 1979;1:718.

23. Mahmoud EL, Benirschke K, Vaucher YE, Poitras $\mathrm{P}$. Motilin levels in term neonates who have passed meconium prior to birth. J Pediatr Gastroenterol Nutr 1988;7:95-9.

24. Behrman RE, editor. Nelson textbook of pediatrics. 14th ed. Philadelphia: WB Saunders, 1992.

25. Cunningham FG, editor. Williams obstetrics. 19th ed. Norwalk, Conn: Appleton \& Lange, 1993.

26. Gooding CA, Gregory GA, Taber P, Wright RR. An experimental model for the study of meconium aspiration of the newborn. Radiology 1971; 100:137-40.

27. Block MF, Kallenberger DA, Kern JD, Nepveux RD. In utero meconium aspiration by the baboon fetus. Obstet Gynecol 1981;57:37-40.

28. Thureen PJ, Hall DM, Hoffenberg A, Tyson RW. Fatal meconium aspiration in spite of appropriate perinatal airway management: pulmonary and placental evidence of prenatal disease. Am J Obstet Gynecol 1997;176:967-75.

29. Brown BL, Gleicher N. Intrauterine meconium aspiration. Obstet Gynecol 1981;57:26-9.

30. Turberville DF, McCaffree MA, Block MF, Krous HF. In utero distal pulmonary meconium aspiration. South Med J 1979;72:535-6.

31. Fanaroff AA. Neonatal perinatal care: diseases of the fetus and infant. 6th ed. St. Louis: Mosby - Year Book, 1997.

32. Tyler DC, Murphy J, Cheney FW. Mechanical and chemical damage to lung tissue caused by meconium aspiration. Pediatrics 1978;62:454-9.

33. Houlihan CM, Knuppel RA. Meconium-stained amniotic fluid. Current controversies. J Reprod Med 1994;39:888-98.

34. Valencia P, Sosa R, Wyble L, Arriaza C, et al. Accuracy of admission chest $x$-ray (CXR) in the prediction of sickness severity in infants with meconium aspiration syndrome (MAS). Clin Res 1993; 41:736A.

35. Burgess AM, Hutchins GM. Inflammation of the lungs, umbilical cord and placenta associated with meconium passage in utero. Review of 123 autopsied cases. Pathol Res Pract 1996;192:1121-8.

36. Stocker JT. The respiratory tract. In Stocker JT, Dehner LP, editors. Pediatric pathology. Philadelphia: Lippincott-Raven, 1992:505.

37. Wiswell TE, Foster NH, Slayter MV, Hachey WE. Management of a piglet model of the meconium aspiration syndrome with high-frequency or conventional ventilation. Am J Dis Child 1992;146: 1287-93.

38. Davey AM, Becker JD, Davis JM. Meconium aspiration syndrome: physiological and inflammatory changes in a newborn piglet model. Pediatr Pulmonol 1993;16:101-8.

39. Perlman EJ, Moore GW, Hutchins GM. The pulmonary vasculature in meconium aspiration. Hum Pathol 1989;20:701-6.

40. Soukka H, Rautanen M, Halkola L, Kero P, Kaapa 
P. Meconium aspiration induces ARDS-like pulmonary response in lungs of ten-week-old pigs. Pediatr Pulmonol 1997;23:205-11.

41. Sun B, Curstedt T, Robertson B. Surfactant inhibition in experimental meconium aspiration. Acta Paediatr 1993;82:182-9.

42. de Beaufort AJ, Pelikan DM, Elferink JG, Berger HM. Effect of interleukin 8 in meconium on invitro neutrophil chemotaxis. Lancet 1998; $352: 102-5$.

43. Wu JM, Wang JN, Wang YJ, Lin YJ, Lin CH, Yeh $\mathrm{TF}$. The role of pulmonary inflammation in the development of pulmonary hypertension in newborn piglet with meconium aspiration syndrome (MAS). Neonat Pulmonol 1997;41:273A.

44. Wu JM, Yeh TF, Lin YJ, Tsai MH, Fan LJ, Lin $\mathrm{CH}$. Increases of leukotriene B4 (LTB4) and D4 (LTD4) and cardiohemodynamic changes in newborn piglets with meconium aspiration (MAS). Neonat Pulmonol 1995;37:357A.

45. Hageman JR, Caplan MS. An introduction to the structure and function of inflammatory mediators for clinicians. Clin Perinatol 1995;22:251-61.

46. Soukka HR, Halkola L, Aho H, Rautanen M, Kero P, Kappa P. Methylprednisolone attenuates the pulmonary hypertensive response in porcine meconium aspiration. Pediatr Res 1997;42:145-50.

47. Soukka HR, Kero PO, Kääpä PO. Biphasic increase in plasma endothelin concentration and pulmonary vascular resistance after meconium aspiration in pigs. Neonatal Pulmonol 1996;39:350A.

48. Mulligan MS, Jones ML, Bolanowski MA, et al. Inhibition of lung inflammatory reactions in rats by an anti-human IL-8 antibody. J Immunol 1993;150: 5585-95.

49. Yokoi K, Mukaida N, Harada A, Watanabe Y, Matsushima K. Prevention of endotoxemia-induced acute respiratory distress syndrome-like lung injury in rabbits by a monoclonal antibody to IL-8. Lab Invest 1997;76:375-84.

50. Moses D, Holm BA, Spitale P, Liu MY, Enhorning G. Inhibition of pulmonary surfactant function by meconium. Am J Obstet Gynecol 1991;164:47781.

51. Sun B, Curstedt T, Robertson B. Surfactant inhibition in experimental meconium aspiration. Acta Paediatr 1993;82:182-9.

52. Bae CW, Takahashi A, Chida S, Sasaki M. Morphology and function of pulmonary surfactant inhibited by meconium. Pediatr Res 1998;44:187-91.

53. Findlay RD, Taeusch HW, Walther FJ. Surfactant replacement therapy for meconium aspiration syndrome. Pediatrics 1996;97:48-52.

54. Auten RL, Notter RH, Kendig JW, Davis JM, Shapiro DL. Surfactant treatment of full-term newborns with respiratory failure. Pediatrics 1991;87: 101-7.

55. Khammash H, Perlman M, Wojtulewicz J, Dunn
M. Surfactant therapy in full-term neonates with severe respiratory failure. Pediatrics 1993;92:135-9.

56. Halliday HL, Speer CP, Robertson B. Treatment of severe meconium aspiration syndrome with porcine surfactant. Collaborative Surfactant Study Group. Eur J Pediatr 1996;155:1047-51.

57. Greenough A. Surfactant replacement therapy for non-respiratory distress syndrome neonatal respiratory disease-research or clinical application? Eur J Pediatr 1995;154(8 Suppl 3):S2-4.

58. Altshuler G, Hyde S. Meconium-induced vasocontraction: a potential cause of cerebral and other fetal hypoperfusion and of poor pregnancy outcome. J Child Neurol 1989;4:137-42.

59. Altshuler G, Arizawa M, Molnar-Nadasdy G. Meconium-induced umbilical cord vascular necrosis and ulceration: a potential link between the placenta and poor pregnancy outcome. Obstet Gynecol 1992;79(5 Pt 1):760-6.

60. Abu-Osba YK. Treatment of persistent pulmonary hypertension of the newborn: update. Arch Dis Child 1991;66(1 Spec No):74-7.

61. Carbonne B, Cudeville C, Sivan H, Cabrol D, Papiernik E. Fetal oxygen saturation measured by pulse oximetry during labour with clear or meconium-stained amniotic fluid. Eur J Obstet Gynecol and Reprod Biol 1997;72(Suppl):S51-5.

62. Ramin KD, Leveno KJ, Kelly MA, Carmody TJ. Amniotic fluid meconium: a fetal environmental hazard. Obstet Gynecol 1996;87:181-4.

63. Hageman JR, Conley M, Francis K, et al. Delivery room management of meconium staining of the amniotic fluid and the development of meconium aspiration syndrome. J Perinatol 1988;8:127-31.

64. Meis PJ, Hall M 3d, Marshall JR, Hobel CJ. Meconium passage: A new classification for risk assessment during labor. Am J Obstet Gynecol 1978;131: 509-13.

65. Rossi EM, Philipson EH, William TG, Kalhan SC. Meconium aspiration syndrome: intrapartum and neonatal attributes. Am J Obstet Gynecol 1989;161: 1106-10.

66. MacDonald D, Grant A, Sheridan-Pereira M, Boylan P, Chalmers I. The Dublin randomized controlled trial of intrapartum fetal heart rate monitoring. Am J Obstet Gynecol 1985;152:524-39.

67. Hobel CJ. Intrapartum clinical assessment of fetal distress. Am J Obstet. Gynecol 1971;110:336-42.

68. Starks GC. Correlation of meconium-stained amniotic fluid, early intrapartum fetal $\mathrm{pH}$, and Apgar scores as predictors of perinatal outcome. Obstet Gynecol 1980;56:604-9.

69. Miller FC, Sacks DA, Yeh SY, et al. Significance of meconium during labor. Am J Obstet Gynecol 1975;122:573-80.

70. Usta IM, Mercer BM, Sibai BM. Risk factors for meconium aspiration syndrome. Obstet Gynecol 1995;86:230-4. 
71. Holtzman RB, Banzhaf WC, Silver RK, Hageman JR. Perinatal management of meconium staining of the amniotic fluid. Clin Perinatol 1989;16:825-38.

72. Jain L, Vidyasagar D. Controversies in neonatal resuscitation. Pediatric Ann 1995;24:540-5.

73. Ting $P$, Brady JP. Tracheal suction in meconium aspiration. Am J Obstet Gynecol 1975;122:767-71.

74. Carson BS, Losey RW, Bowes WA Jr, Simmons MA. Combined obstetric and pediatric approach to prevent meconium aspiration syndrome. Am J Obstet Gynecol 1976;126:712-15.

75. Greenough A. Meconium aspiration syndrome-prevention and treatment. Early Hum Dev 1995; 41:183-92.

76. Desmond MD, Moore J, Lindley JE, et al. Meconium staining of the amniotic fluid: a marker of fetal hypoxia. Obstet Gynecol 1957;9:91-103.

77. Driscoll SG, Smith CA. Neonatal pulmonary disorders. Pediatr Clin North Am 1962;9:325-52.

78. Walker J. Fetal anoxia. J Obstet Gynaecol Brit Emp 1954;61:162-80.

79. White VT. The significance and management of meconium in the liquor amnii during labour. Med $\mathbf{J}$ Aust 1955;1:641-4.

80. Mercer BM, McNanley T, O’Brien JM, Randal L, Sibai BM. Early versus late amniotomy for labor induction: a randomized trial. Am J Obstet Gynecol 1995;173:1321-5.

81. Goffinet F, Fraser W, Marcoux S, Breart G, Moutquin JM, Daris M. Early amniotomy increases the frequency of fetal heart rate abnormalities. Amniotomy Study Group. Br J Obstet Gynaecol 1997; 104:548-53.

82. Byrne DL, Gau G. In utero meconium aspiration: an unpreventable cause of neonatal death. $\mathrm{Br} \mathrm{J} \mathrm{Ob-}$ stet Gynaecol 1987;94:813-4.

83. Dooley SL, Pesavento DJ, Depp R, Socol ML, Tamura RK, Wiringa KS. Meconium below the vocal cords at delivery: correlation with intrapartum events. Am J Obstet Gynecol 1985;153:76770.

84. Weismiller DG. Transcervical amnioinfusion. Am Fam Physician 1998;57:504-10.

85. Dye T, Aubry R, Gross S, Artal R. Amnioinfusion and the intrauterine prevention of meconium aspiration. Am J Obstet Gynecol 1994;171:1601-5.

86. Hofmeyr GJ, Gulmezoglu AM, Nikodem VC, de Jager M. Amnioinfusion. Eur J Obstet Gynecol Reprod Biol 1996;64:159-65.

87. Tabor BL, Maier J. Polyhydramnios and elevated intrauterine pressure during amnioinfusion. Am J Obstet Gynecol 1987;156:130-1.

88. Ogundipe OA, Spong CY, Ross MG. Prophylactic amnioinfusion for oligohydramnios: a reevaluation. Obstet Gynecol 1994;84:544-8.

89. Miyazaki FS, Taylor NA. Saline amnioinfusion for relief of variable or prolonged decelerations. A pre- liminary report. Am J Obstet Gynecol 1983;146: 670-8.

90. Strong TH Jr, Hetzler G, Sarno AP, Paul RH. Prophylactic intrapartum amnioinfusion: a randomized clinical trial. Am J Obstet Gynecol 1990; 162:1370-5.

91. Dibble LA, Elliott JP. Possible amniotic fluid embolism associated with amnioinfusion. J Matern Fetal Med 1992;1:263-6.

92. Wenstrom KD, Parsons MT. The prevention of meconium aspiration in labor using amnioinfusion. Obstet Gynecol 1989;73:647-51.

93. Sadovsky Y, Amon E, Bade ME, Petrie RH. Prophylactic amnioinfusion during labor complicated by meconium: a preliminary report. Am J Obstet Gynecol 1989;161:613-7.

94. Macri CJ, Schrimmer DB, Leung A, Greenspoon JS, Paul RH. Prophylactic amnioinfusion improves outcome of pregnancy complicated by thick meconium and oligohydramnios. Am J Obstet Gynecol 1992;167:117-21.

95. Cialone PR, Sherer DM, Ryan RM, Sinkin RA, Abramowicz JS. Amnioinfusion during labor complicated by particulate meconium-stained amniotic fluid decreases neonatal morbidity. Am J Obstet Gynecol 1994;170:842-9.

96. Lo KW, Rogers M. A controlled trial of amnioinfusion: the prevention of meconium aspiration in labour. Aust N Z Obstet Gynaecol 1993;33:51-4.

97. Eriksen NL, Hostetter M, Parisi VM. Prophylactic amnioinfusion in pregnancies complicated by thick meconium. Am J Obstet Gynecol 1994;171:102630.

98. Spong CY, Ogundipe OA, Ross MG. Prophylactic amnioinfusion for meconium-stained amniotic fluid. Am J Obstet Gynecol 1994;171:931-5.

99. Cusick W, Smulian JC, Vintzileos AM. Intrapartum use of fetal heart rate monitoring, contraction monitoring, and amnioinfusion. Clin Perinatol 1995;22:875-906.

100. Rogers MS, Lau TK, Wang CC, Yu KM. Amnioinfusion for the prevention of meconium aspiration during labour. Aust N Z Obstet Gynaecol 1996;36: 407-10.

101. Usta IM, Mercer BM, Aswad NK, Sibai BM. The impact of a policy of amnioinfusion for meconiumstained amniotic fluid. Obstet Gynecol 1995;85: 237-41.

102. DeMeeus JB, D'Halluin G, Bascou V, Ellia F, Magnin G. Prophylactic intrapartum amnioinfusion: a controlled retrospective study of 135 cases. Eur J Obstet Gynecol Reprod Biol 1997;72:141-8.

103. Spong CY, Ogundipe A, Ross MG. Amnioinfusion and the intrauterine prevention of meconium aspiration. Am J Obstet Gynecol 1995;173:671-2.

104. Spong CY. Amnioinfusion. Indications and controversies. Contemp Obstet Gynecol 1997;42: $138-159$. 
105. Wiswell TE, Tuggle JM, Turner BS. Meconium aspiration syndrome: have we made a difference? Pediatrics 1990;85:715-21.

106. Rossi C, Nascimento SD, Fernanda $M$, et al. Should obstetricians clear the airways of newborn infants with meconium stained amniotic fluid (MSAF)? Pediatr Res 1997;41:173A.

107. Raju TN, Vidyasagar D, Torres C, Grundy D, Bennett EJ. Intracranial pressure during intubation and anesthesia in infants. J Pediatr 1980;96:860-2.

108. Murphy JD, Vawter GF, Reid LM. Pulmonary vascular disease in fatal meconium aspiration. J Pediatr 1984;104:758-62.

109. VanDyke RB, Spector SA. Transmission of herpes simplex virus type 1 to a newborn infant during endotracheal suctioning for meconium aspiration. Pediatr Infect Dis 1984;3:153-6.

110. Ballard JL, Musial MJ, Myers MG. Hazards of delivery room resuscitation using oral methods of endotracheal suctioning. Pediatr Infect Dis 1986;5: 198-200.

111. Kresch MJ, Brion LP, Fleischman AR. Delivery room management of meconium-stained neonates. J Perinatol 1991;11:46-8.

112. Coltart TM, Byrne L, Bates SA. Meconium aspiration syndrome. A 6-year retrospective study. $\mathrm{Br} \mathrm{J}$ Obstet Gynaecol 1989;96:411-4.

113. Yoder BA. Meconium-stained amniotic fluid and respiratory complications: impact of selective tracheal suction. Obstet Gynecol 1994;83:77-84.

114. Peng TC, Gutcher GR, Van Dorsten JP. A selec- tive aggressive approach to the neonate exposed to meconium-stained amniotic fluid. Am J Obstet Gynecol 1996;175:296-301.

115. Linder N, Aranda JV, Tsur M, et al. Need for endotracheal intubation and suction in meconiumstained neonates. J Pediatr 1988;112:613-5.

116. Chameides L, Hazinski MF. Textbook of pediatric advanced life support. Dallas: American Heart Association, 1997.

117. Guidelines for cardiopulmonary resuscitation and emergency cardiac care. Part VII. Neonatal resuscitation. Emergency Cardiac Care Committee and Subcommittees, American Heart Association. JAMA 1992;268:2276-81.

118. Bloom RS, Cropley C, AHA/AAP Neonatal Resuscitation Program Steering Committee. Textbook of neonatal resuscitation. Elk Grove Village, Ill: American Academy of Pediatrics, 1994.

119. Bent RC, Wiswell TE, Chang A. Removing meconium from infant tracheae: what works best? Am J Dis Child 1992;140;1084-9.

120. Hernandez C, Little BB, Dax JS, Gilstrap LC 3rd, Rosenfeld CR. Prediction of the severity of meconium aspiration syndrome. Am J Obstet Gynecol 1993;169:61-70.

121. Davis RO, Philips JB, Harris BA Jr, Wilson ER, Huddleston JF. Fatal meconium-aspiration syndrome occurring despite airway management considered appropriate. Am J Obstet Gynecol 1985; 151:731-6. 